\title{
Efficiency of a System for the Separate Collection of the Biowaste from Municipal Solid Waste. A Spanish Pilot Case Study
}

\section{Antonio Gallardo}

Universitat Jaume I

Francisco J. Colomer-Mendoza ( $\square$ fcolomer@uji.es )

Universitat Jaume I https://orcid.org/0000-0002-8666-6238

\section{Mar Carlos}

Universitat Jaume I

\section{Cristóbal Badenes}

Universitat Jaume I

\section{Natalia Edo-Alcón}

Universitat Jaume I

Joan Esteban-Altabella

Universidad Jaume I

\section{Research}

Keywords: biowaste, source-separation, container, separate collection, kerbside system

Posted Date: November 5th, 2020

DOl: https://doi.org/10.21203/rs.3.rs-101276/v1

License: (9) (i) This work is licensed under a Creative Commons Attribution 4.0 International License. Read Full License 
1 Efficiency of a system for the separate collection of the biowaste from municipal

4 Gallardo, Antonio

5 Department of Mechanical Engineering and Construction.. Universitat Jaume I. Ave.

6 Vicent Sos Baynat, s/n. 12071 Castellón (España)

7

8 Colomer-Mendoza, Francisco J.*

9 Department of Mechanical Engineering and Construction.. Universitat Jaume I. Ave. 10 Vicent Sos Baynat, s/n. 12071 Castellón (España)

$11 *$ Corresponding author: Colomer Mendoza, F.J. fcolomer@uji.es

Carlos M.; Badenes C. ${ }^{1}$; Edo-Alcón N. ${ }^{1}$; Esteban-Altabella J. ${ }^{1}$

Department of Mechanical Engineering and Construction.. Universitat Jaume I. Ave. Vicent Sos Baynat, s/n. 12071 Castellón (España)

\section{Badenes, Cristóbal}

Department of Mechanical Engineering and Construction.. Universitat Jaume I. Ave. Vicent Sos Baynat, s/n. 12071 Castellón (España)

\section{Edo-Alcón, Natalia}

Department of Mechanical Engineering and Construction.. Universitat Jaume I. Ave. Vicent Sos Baynat, s/n. 12071 Castellón (España)

\section{Esteban-Altabella, Joan}

Department of Mechanical Engineering and Construction.. Universitat Jaume I. Ave. Vicent Sos Baynat, s/n. 12071 Castellón (España) 
Abstract

30

Background:

According to EU regulations, member states shall take measures to encourage the recycling of biowaste in a way that fulfils a high level of environmental protection. In Spain, the separate collection of biowaste is only implemented in some regions. For this reason, a pilot scheme based on an information campaign and the location of a specific brown container for biowaste in specific zones of the city was carried out in Castellón de la Plana (Spain) over a period of six months. In this period, the collection and composition of the biowaste was monitored in depth with the goal of determining the evolution of the efficiency of the new collection system over time. Results:

In the zones, the quality rate in the biowaste container increased as the pilot study progressed, finally reaching $90 \%$. The rate of biowaste separation also increased in the three zones over time, although in different ways, which means that there is greater collaboration on the part of citizens. On the other hand, an analysis of the rate of net biowaste daily collection from zones 2 and 3 has shown that their value increases as the rate of containerization of biowaste decreases.

47 Conclusions:

In order to obtain better results in the biowaste quality rate it will be necessary to increase the containerization of biowaste, that is, to reduce the distance from the citizen to the container. It can thus be said that there is a positive evolution of the experience, which boosts confidence when it comes to implementing the system throughout the city.

Key words: biowaste, source-separation, container, separate collection, kerbside system 


\section{1.- Background}

The European Union (EU) must take taction to guarantee the hierarchy of waste to obtain recycled products of high quality. Therefore, the EU Member States will have to achieve the separation of bio-waste, which will contribute to the protection of the environment (Directive 2018/851 EU; Directive 2008/98/EC). In addition, important benefits would be obtained such as the reduction of greenhouse gas emissions, generation of biogas and production of good quality compost. This will contribute to the improvement of the quality of the soil, the use and efficiency of resources and energy self-sufficiency (European Commission 2019).

The main threat of the mismanagement of the bio-waste is the production of methane by anaerobic fermentation in landfills. These emissions accounted for 3\% of total greenhouse gas emissions in the EU-15 in 1995. The second threat, especially from municipal biological waste, is the generation of leachate, which can be an important source of contamination if it is not controlled (Závodská et al., 2014). In Ireland, for example, it is not allowed to receive wastes in landfills if they have not been previously treated according to the standards of the Irish Environmental Protection Agency (Závodská et al., 2014). Moreover, Member States shall ensure that, by 31 December 2023, biowaste is either separated and recycled at source, or is collected separately and is not mixed with other types of waste.

In the study by Tatano et al. (2017), the waste generated at a restaurant in a coastal tourist area in central Italy (Marche Region, Adriatic Sea side) was characterized and the separate collection implemented was evaluated. The characterization of the waste generated at the restaurant showed considerable incidences of food (28.2\%), glass (22.6\%), paper/cardboard (19.1\%) and plastic (17.1\%) (Tatano et al., 2017). Other works have indicated that biodegradable components dominate the characterization at $54.83 \%$ 
of the total, followed by inert, ash and debris at $21.06 \%$, paper at $8.77 \%$, plastic at $8.18 \%$, glass and ceramics at $4.45 \%$ and metals at 2.71\% (Majid and Hwee, 2007; Dangi et al., 2011; Pirani and Arafat, 2014; Tatano et al., 2017).

Experiences carried out in Latvia indicated that $32.9 \%$ of recyclable waste is not properly separated, and $29.2 \%$ is bio-waste. This implies that almost $60 \%$ of the potentially recyclable waste in this country could be used if separated at the source, promoting a circular economy (Kubule et al., 2019).

In some German cities, separate collection of household biowaste affects the quality and final composition of the recovered materials. In fact, when the biowaste was separated, the rest of the waste was reduced by up to $30 \%$. Furthermore, the residual waste had less humidity, which improves the efficiency of the incineration plants (Schuch et al., 2017). In the food industry, the efficient separation of bio-waste is even more important due to the large quantities of waste that is produced. Separation at source in the industries and factories is key to improve the quality of the resources obtained from bio-waste. Therefore, on the one hand, education and awareness of society and companies is essential, and on the other hand, investment in support facilities (Wang et al., 2020).

Sometimes, when separation is done properly, investments in source separation are very profitable. As an example, in Southampton (UK), separate collection of bio-waste could save the council $£ 690,000$ each year, despite having to incur a significant cost on vehicle adaptation and construction of the transfer stations (Bees and Williams, 2017). In two UK cities (Cardiff and Southampton) a survey of 100 people on recycling, awareness and waste separation was carried out. In areas where selective collection of food was carried out (Cardiff), recycling rates and citizen satisfaction were higher. In the area with no separate collection (Southampton) over $75 \%$ of respondents said they would like to have a separate collection system and would participate if available (Bees and Williams, 2017). 
In Portugal, a comparative study was carried out on the costs of separate collection. It was concluded that the cases of separate collection of bio-waste did not imply an overall increase in costs in the service, they could even decrease them if more than $40 \%$ of the population (threshold for the case study) participate in the system (Gomes et al., 2008).

On the other hand, the collection system, the levels of separation at source, the urban density of the village and the obligation to use compostable bags are factors which influence to reduce the percentage of inappropriate material in the bio-waste fraction (Puig-Ventosa et al., 2013).

In Spanish cities, following the EU regulations, separate collection of bio-waste is being applied. Taking into account the European standards and the different fractions that can be separated, there are 8 selective collection systems (Gallardo et al., 2012) like the fivecontainers model: glass, paper-cardboard, light packaging, bio-waste and reject, although with little implementation.

This paper presents the results obtained in a pilot project for the source-separation collection of biowaste applied to the city of Castelló de la Plana (in eastern Spain). First, a methodology for the development of the pilot project is proposed and the degree of efficiency of the biowaste source-separation was determined in order to design the model to be implemented throughout the city. For this purpose, first of all, a set of indicators were defined. Second, details of the pilot experiment are given. The results of the experiment were treated statistically in order to organize the information. Both the waste from the mixed container and that from the new biowaste container were characterized to all this work, conclusions about the implementation of a new biowaste container in a town were then extracted. 


\section{2.- Methodology}

130 The study was divided into five stages: (i) objectives, indicators and scope of the study, (ii) identification of the study area, (iii) definition and dissemination of an information and awareness campaign (information campaign), (iv) experimental design, and (v) data analysis.

\subsection{Objectives, indicators and scope of the study}

The aim of the pilot study is to determine the degree of the efficiency of the biowaste separate collection system over time and how the type of separate collection affects it. For this purpose, the following specific objectives have been proposed:

- Determine the degree of efficiency of the biowaste collection system.

- Determine the degree of the variation in efficiency over time.

- Determine whether the selective collection model can influence the degree of efficiency of the biowaste collection system.

- Determine the variation in the composition of the mixed waste (mx) container with or without selective collection of the biowaste fraction.

In order to determine the degree of efficiency of a collection system, first of all, it is necessary to define a number of indicators. In this work, efficiency is defined in terms of the extent to which clean materials are recovered at source, that is to say, materials deposited in containers. It is expressed a set of indicators defined by Gallardo et al., 2010 such as the separation rate (SR), the net separation rate (NSR) and the quality in container rate (QCR) shown in Equations 1,2 and 3.

$$
\begin{aligned}
& S R_{i}(\%)=100 \cdot \frac{\text { amount of waste collected in container for } i}{\text { total amount of } i \text { waste generated }} \\
& N S R_{i}(\%)=100 \cdot \frac{\text { amount of } i \text { waste collected in container for } i}{\text { total amount of } i \text { waste generated }}
\end{aligned}
$$




$$
\operatorname{QCR}_{i}(\%)=100 \cdot \frac{\text { amount of waste collected correctly in container for } i}{\text { total amount of } \text { waste collected in container for } i}
$$

154

The $\mathrm{SR}_{\mathrm{i}}$ and $\mathrm{QCR} \mathrm{R}_{\mathrm{i}}$ indicators are two useful indicators to know the amount of inappropiate materials in the container. In the case of separate collection of the biowaste, the inappropriate material consists of plastic, glass, paper-cardboard, brick, etc. In order to compare the collection in different scenarios, the daily collection rate (DCR) and the containerization rate $(\mathrm{CR})$ were defined (Equations 4 and 5):

$D C R_{i}(\mathrm{~kg} /$ in $\cdot$ day $)=\frac{\text { amount of } i \text { waste collected in one day in an area }}{\text { inhabitant in this area }}$

$C R($ inh/container $)=\frac{\text { inhabitants }}{\text { containers }}$

The scope of the study has been focused only on the previous mixed waste fraction and the new biowaste fraction. The pilot study lasted six months, from 23 January to 20 July 2017. Previously, the information and awareness campaign for citizens was carried out, which lasted three months.

\subsection{Identification of the study area}

Castelló de la Plana is a coastal city on the Mediterranean Sea $\left(39.9857^{\circ} \mathrm{N} 0.0494^{\circ} \mathrm{W}\right)$, located in the Valencian Community in eastern Spain, with a population of 170,990 inhabitants in 2016 and a Mediterranean climate. Currently, in this city, people separate the waste into four fractions: mixed waste (biowaste and reject), paper/cardboard, lightpackaging (beverage cartons, plastic and cans) and glass.

The mixed waste fraction is collected by means of three kerbside systems: (i) mechanical back-loading truck and $340 \mathrm{~L}$ containers. The distance between containers is $20-30 \mathrm{~m}$; (ii) automatic side-loading truck and 1,100 L containers. The distance between containers is 50-60 m, and (iii) automatic side-loading truck and 3,200 L containers. The distance 
176 between containers is $100-120 \mathrm{~m}$. Citizens deposit the glass fraction, paper/cardboard

177 fraction and light-packaging fraction in drop-off areas.

178 The frequency of collection of mixed waste $(\mathrm{mx})$ is six days a week. The collection of 179 mixed waste in 2016 was 56,875 tons, which represents a $D_{C R}$ mx $0.91 \mathrm{~kg} / \mathrm{inh} \cdot$ day.

180 To carry out the pilot study, it was decided to define three study areas, one for each 181 kerbside system. Table 1 shows the characteristics of each area. The zones have different numbers of inhabitants and containers.

Table 1: Characteristics of the study areas

\begin{tabular}{|c|c|c|c|c|c|}
\hline \multirow[b]{2}{*}{ Zone } & \multirow[b]{2}{*}{ Inhabitants } & \multirow[b]{2}{*}{$\begin{array}{l}\text { Collection } \\
\text { system }\end{array}$} & \multicolumn{3}{|c|}{ Containers } \\
\hline & & & Vol. (L) & $\begin{array}{c}\text { No. } \\
\text { Mixed } \\
\text { waste }\end{array}$ & $\begin{array}{l}\mathrm{N}^{\circ} \text { No. } \\
\text { Biowaste }\end{array}$ \\
\hline $\begin{array}{c}\text { Zone } 1 \\
\text { (city centre) }\end{array}$ & 3,956 & $\begin{array}{l}\text { mechanical } \\
\text { back-loading } \\
\text { truck }\end{array}$ & 340 & 72 & 40 \\
\hline $\begin{array}{c}\text { Zone } 2 \\
\text { (north of the city) }\end{array}$ & 1,451 & $\begin{array}{l}\text { mechanical } \\
\text { back-loading } \\
\text { truck }\end{array}$ & 1,100 & 18 & 10 \\
\hline $\begin{array}{c}\text { Zone } 3 \\
\text { (west city) }\end{array}$ & 2,244 & $\begin{array}{l}\text { automatic side- } \\
\text { loading truck }\end{array}$ & 3,200 & 8 & 6 \\
\hline
\end{tabular}

Zone 1 is located in the city centre, which corresponds to the old city. It is an area where a low-density residential area is combined with commercial and restaurant areas. Zone 2 is located in the northern district of the city. It corresponds to a wide area with a highdensity residential area with several green areas and little commerce. Zone 3 is located in the west of the city and has similar characteristics to Zone 2. Finally, Zone 4 was also defined, close to Zone 2, where the selective collection of biowaste was not implemented. Samples were taken in this area to determine the composition of the mixed waste container of the current MSW collection system in Castelló de la Plana.

\subsection{Information campaign}


Before starting the pilot study, an information and awareness campaign was carried out in Zone 1, Zone 2 and Zone 3. This consisted in informative talks given in neighbours' associations about the pilot scheme, its objective, the environmental benefits of its implementation and the importance of their participation. The inhabitants were provided with a $10 \mathrm{~L}$ brown plastic bin (Fig. 1 left) and biodegradable bags to separate their biowaste. They were also informed about the types of waste that they should deposit in that brown bin and in which container they should finally deposit the biowaste bags (brown container in the drop-off areas, Fig. 1 right). Both the brown bin and the brown container have an identification sticker indicating the material to be deposited. The mixed waste container in the drop-off areas is actually green, so there is a clear difference.
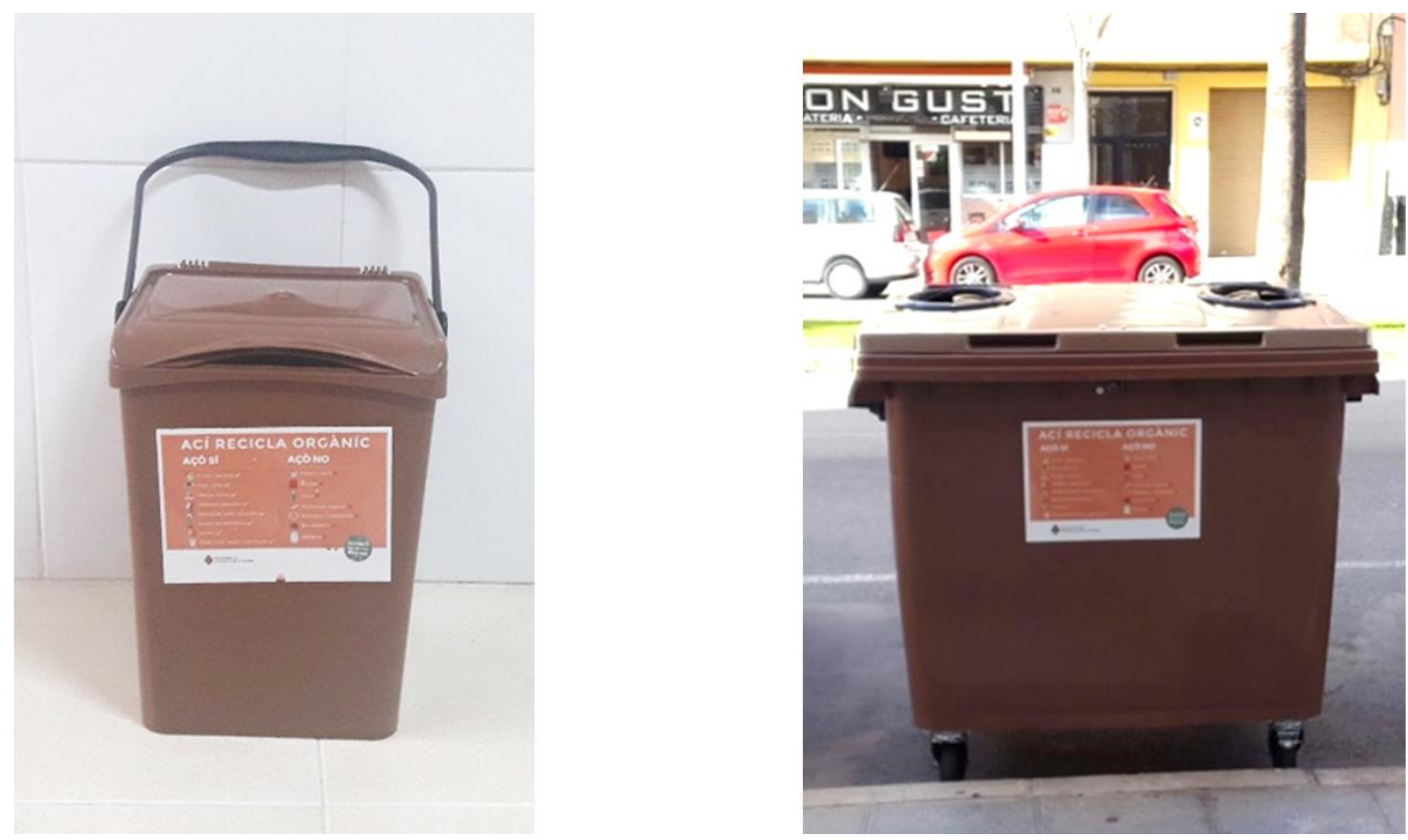

Fig. 1. $10 \mathrm{~L}$ bin (left) and 1,100 L container (right)

\subsection{Experimental design}

210 The experiment consisted in defining the number, adequate volume and location of the biowaste containers in each zone (Zone 1, Zone 2 and Zone 3) and their collection. The 
212 decision was made to install containers with the same volume as the mixed waste containers but with a different colour (brown), the distinctive colour of the corresponding bins that is reminiscent of food and garden waste (i.e. biowaste). Brown is the colour that is used exclusively for biowaste collection throughout Europe as opposed to the different colours that may be used for the bins for the other components (Calabro and Komilis, 2019). The number of biowaste containers was lower than the number of mixed waste containers due to economic reasons. Table 1 shows the number of biowaste containers located in each area.

Containers were collected three times a week, since a large volume of biowaste was not expected. Each zone had an independent collection route. Once the collection was complete, the collection truck was weighed at the treatment plant, so daily collection data were available for the three areas. In Zone 1, due to different technical reasons, collection began 6 weeks later than in the rest.

Sampling and laboratory characterization were then scheduled to determine the average composition of the biowaste in the brown container in each of the three areas. Sampling and characterization were also scheduled to determine the composition of the mixed waste container in zone 4. To calculate the number of samples needed and their size, the "Methodology developed by the European Commission in 2004 for the Analysis of Solid Waste (SWA-Tool)" was used.

In order to determine the composition, the waste was separated into 13 categories: biowaste (food and garden waste), metal packaging (cans, etc.), other metals, clean paper/cardboard, dirty paper/cardboard, plastic packaging (food and beverage packaging, plastic bags, etc.), other plastics, sanitary cellulose, beverage carton packages, textile, glass packaging, others (flat glass, rubber and leather, wood, hazardous waste, electric and electronic wastes and inert) and fines (material less than $10 \mathrm{~mm}$ ). 
237 After the experimental stage, the results obtained in the four zones were analysed.

\subsection{Data analysis}

240 In order to know the sample size, the SWA-Tool methodology was used. The number of samples

241 was determined using equation 6.

242 where:

$$
n=\left(\frac{t_{\alpha ; n-1} \cdot V C}{\varepsilon}\right)^{2}
$$

$\mathrm{n}$ is the number of samples required

$\mathrm{t}_{a ; \mathrm{n}-1}$ is the deviation from the accepted mean value to achieve the desired confidence level ( $\square$ -

1), for the " $t$ " distribution.

$246 \mathrm{VC}$ (variation coefficient) is the variance that we hope to find in the population (expressed as a

247 decimal)

$248 \varepsilon$ is the maximum margin of error (expressed as a decimal)

249 To calculate $\mathrm{VC}$, it is necessary to know previously the data about the mean and the standard deviation (st. dev.) of the waste composition.

Several statistical tests were carried out to evaluate the differences between datasets using the free software software $\mathrm{R}$ commander ${ }^{\odot}$. The tests used were the Shapiro-Wilk test (test for normal distribution) to decide which statistical test to use, the Levene test (test for homogeneity of variances), ANOVA to compare the means and to verify differences among several tests, the Kruskal-Wallis test to compare two samples (used when data are not normally distributed) and finally, the Dunn post-hoc test that was used to perform multiple comparisons by pairs to identify the means that were different.

\section{3.- Results and discussion}

\subsection{Size and number of samples}


262 To calculate the minimum number of samples needed to determine the composition of 263 biowaste and mixed waste in the containers, the chosen confidence level was $95 \%$, so the 264 value $t_{\alpha ; n-1}=1.960$. The means and standard deviations were obtained from previous 265 characterizations carried out by the Castelló de la Plana City Council. For the calculation, only the biowaste fraction has been considered, since it is the one of interest for the study. Finally, a margin of error of $10 \%$ has been assumed.

Table 2 shows the data needed to perform the calculation and the results obtained after applying Equation 1.

Table 2: Sample number calculation

\begin{tabular}{cccccccc}
\hline Container & Waste fraction & $\begin{array}{c}\text { Mean } \\
(\boldsymbol{\%})\end{array}$ & $\begin{array}{c}\text { Earlier data } \\
\text { st. dev. } \\
(\boldsymbol{\%})\end{array}$ & $\begin{array}{c}\text { VC } \\
\text { (a decimal) }\end{array}$ & $\boldsymbol{t}_{\mathbf{0 . 0 5} ; \infty}$ & $\boldsymbol{\varepsilon}$ & $\mathbf{n}$ \\
\hline biowaste & biowaste & 77.02 & 10.12 & 0.13 & 1.96 & 0.1 & 7 \\
mixed waste & biowaste & 52.55 & 4.46 & 0.08 & 1.96 & 0.1 & 3 \\
\hline
\end{tabular}

According to Table 2 and Equation 1, it will be necessary to take at least seven samples in each of the three zones to determine the biowaste fraction with a confidence level of $95 \%$ and an error of $10 \%$. In the case of the mixed waste container, only three samples will be necessary in each of the four areas.

One of the objectives of the study was to determine the variation in the composition of the biowaste container over the duration of the experiment, so it was decided to increase the number of samples and characterize 22 samples in Zone 1, 27 samples in Zone 2 and 25 samples in Zone 3.

In the case of the biowaste container, the samples were evenly distributed over the six months of the pilot study. In the case of the mixed waste container, the sampling was concentrated in the last four months in the four areas. Regarding the minimum sample size required, the SWA-Tool recommends that it should be equal to the volume of a container similar to those existing in the study area, without 
taking into account the amount of waste contained within it. It also establishes that if there are containers of different sizes in the same study area, the volume of the most commonly used type of container should be chosen as the sample size. Therefore, the chosen sample sizes correspond to the volume of the existing containers in each area. For Zone 4, the chosen volume was $1,100 \mathrm{~L}$.

\section{2.- Quality container rate in biowaste collection and variation over time}

One of the indicators of the efficiency of the biowaste (bw) collection system is the Quality in Container Rate $\left(\mathrm{QCR}_{\mathrm{bw}}\right)$. The percentage of biowaste in the container coincides with this indicator.

The average composition for each of the three zones is shown in Table 3. It can be seen that in the three areas, the percentage of biowaste is high, between $79.75 \%$ and $82.74 \%$, although there is still around $20 \%$ of inappropriate, which will end up being a reject in the treatment plant. These $\mathrm{QCR}_{\mathrm{bw}}$ values are lower than those obtained in an experiment carried out in the city of Reggio Calabria (Italy), where the biowaste bins received $89 \%$ of biowaste, after a public awareness campaign. But in this case, the separate collection of biowaste was door-to-door and had been in place for several years (Calabro and Komilis, 2019). However, the values are similar to those recorded in Catalonia (Spain), where the majority of characterizations of the biowaste fraction contained between $10 \%$ and $20 \%$ of inappropriate material. However, in some cities this figure was as high as $40 \%$ or $50 \%$ (Alvarez et al., 2008). On the other hand, in an experience experiment with only 425 inhabitants, Boelens et al. (2013) obtained very low inappropriate materials values of around 3\% in Antwerp (Belgium).

The fraction of "fines" is the most abundant in the inappropriate part. This is a fraction with materials less than $10 \mathrm{~mm}$ in size, such as dirt, dust, stones, microplastics, metals, 
etc. Secondly, there is plastic packaging, consisting of bags, bottles, dirty food packaging, etc. The amount of non-biodegradable bags that appeared could have been lower if a greater number of biodegradable bags had been distributed to citizens. In fact, the use of modern compostable bags is starting to be implemented in some European countries and encourages separation of biowaste at source. These compostable bags are made of biodegradable polymers, often from renewable sources (Puyuelo et al., 2013). Furthermore, in a region of Spain (Catalonia) a pilot project has been carried out since 1996 on separate collection of bio-waste. Biodegradable waste from homes, shops, markets, restaurants, etc. are collected using a door-to-door system. Currently, this system covers $95 \%$ of the population with high participation, also due to the previous distribution of bins and biodegradable bags to citizens. Biowaste is treated by means of a combined anaerobic digestion and composting systems (Urban Waste, 2020). In other works, the relationship between the separate collection system and the quality of the biowaste was verified. The door-to-door collection system was the one with the highest quality of biowaste (Alvarez et al., 2008).

Citizens identify dirty food packaging with the fraction of biowaste and, therefore, for future research, citizens should be informed that these materials must be cleaned and placed in the appropriate container. Dirty paper, which is also identified as biowaste, was also found in this fraction but this is not a problem since it is biodegradable. Finally, very little glass was found, except in Zone 1. As Zone 1 is a restaurant and commercial area, wine bottles appeared in some characterizations.

If the composition of the biowaste container is compared with that of mixed waste (Table 4), a clear difference is observed in all the fractions, mainly in the biowaste with a notable increase, which is why the separate collection system has been successful. Something similar happened in similar experiments carried out in a Mediterranean area such as the 


\begin{tabular}{lrrrrrrr}
\hline & \multicolumn{2}{c}{ Zone 1 } & \multicolumn{2}{c}{ Zone 2 } & \multicolumn{2}{c}{ Zone 3 } \\
& mean & st. dev. & mean & st. dev. & mean & st. dev. \\
\hline Biowaste & 79.75 & 11.30 & 82.74 & 5.57 & 81.18 & 8.78 \\
Inappropriate & 20.25 & 11.30 & 17.25 & 5.52 & 18.82 & 8.78 \\
Metal packaging & 0.37 & 0.33 & 0.21 & 0.08 & 0.16 & 0.11 \\
Other metals & 0.01 & 0.02 & 0.01 & 0.02 & 0.03 & 0.04 \\
Clean paper/cardboard & 0.00 & 0.00 & 0.09 & 0.13 & 0.07 & 0.09 \\
Dirty paper/cardboard & 2.18 & 0.94 & 2.50 & 0.42 & 3.41 & 0.51 \\
Plastic packaging & 6.02 & 2.00 & 4.45 & 0.47 & 5.97 & 0.83 \\
Other plastics & 0.51 & 0.43 & 0.21 & 0.08 & 0.49 & 0.24 \\
Sanitary cellulose & 0.40 & 0.63 & 0.19 & 0.18 & 0.18 & 0.12 \\
Beverages cartons & 0.09 & 0.23 & 0.07 & 0.03 & 0.17 & 0.20 \\
Textile & 0.00 & 0.00 & 0.02 & 0.02 & 0.33 & 0.33 \\
Others & 0.13 & 0.26 & 0.70 & 0.28 & 0.11 & 0.20 \\
Glass packaging & 2.13 & 2.00 & 0.44 & 0.57 & 0.42 & 0.23 \\
Fines & 8.41 & 1.72 & 8.35 & 0.77 & 7.48 & 0.97 \\
\hline
\end{tabular}
separation systems has increased considerably, which was due to the incentives from the local government to improve the quality of the biodegradable fraction of municipal solid waste (Puyuelo et al., 2013). However, the level of separate collection of biological waste in the EU countries is very different. In countries such as Austria, Flanders (Belgium), Germany, the Netherlands, Norway, Sweden and Switzerland, the separate collection of bio-waste has been in place for more than 15 years. Other countries such as Estonia, Finland, France, Ireland, Italy, Slovenia and the United Kingdom have been gradually implementing these systems over the last 15 years, while Bulgaria, Cyprus, Croatia, the Czech Republic, Greece, Hungary, Latvia, Lithuania, Malta, Poland, Portugal, Romania, Slovakia and Spain are still applying separation (albeit unevenly) in their regions (ECN, 2020).

Table 3: Biowaste container composition (\%)

Table 3 shows that there are no significant differences in the biowaste percentages among the three zones, and therefore in their $\mathrm{QCR}_{\mathrm{bw}}$. To determine whether it was true, it was necessary to demonstrate it statistically. For this reason, an Analysis of Variance was carried out. In this case,
} 
352 it was verified that normality can't be assumed for the biowaste fraction. Consequently, the

353 Krustal Wallis test was used with a confidence level of $95 \%(\alpha=0.05)$.

354 After comparing the means, a p-value of 0.814 (p-value > 0.05) was obtained, so it could 355 be stated with $95 \%$ confidence that there are no statistically significant differences in the 356 percentage of biowaste between the three areas. This fact indicates that the citizens who 357 participated in the experience behaved in the same way in the three areas and that they all 358 reached the same level of knowledge regarding what should be deposited in the biowaste 359 container.

360 The variation in the $\mathrm{QCR}_{\mathrm{bw}}$ of the biowaste container over time can be seen in Fig. 2. In 361 all zones the $\mathrm{QCR}_{\mathrm{bw}}$ increased as the pilot study progressed. Zone 1 underwent the 362 greatest increase, going from $70 \%$ at the beginning of the experiment to $90 \%$ at the end. 363 In Zones 2 and 3, the progress was smoother because the initial QCR $\mathrm{bw}_{\mathrm{b}}$ data were higher. 

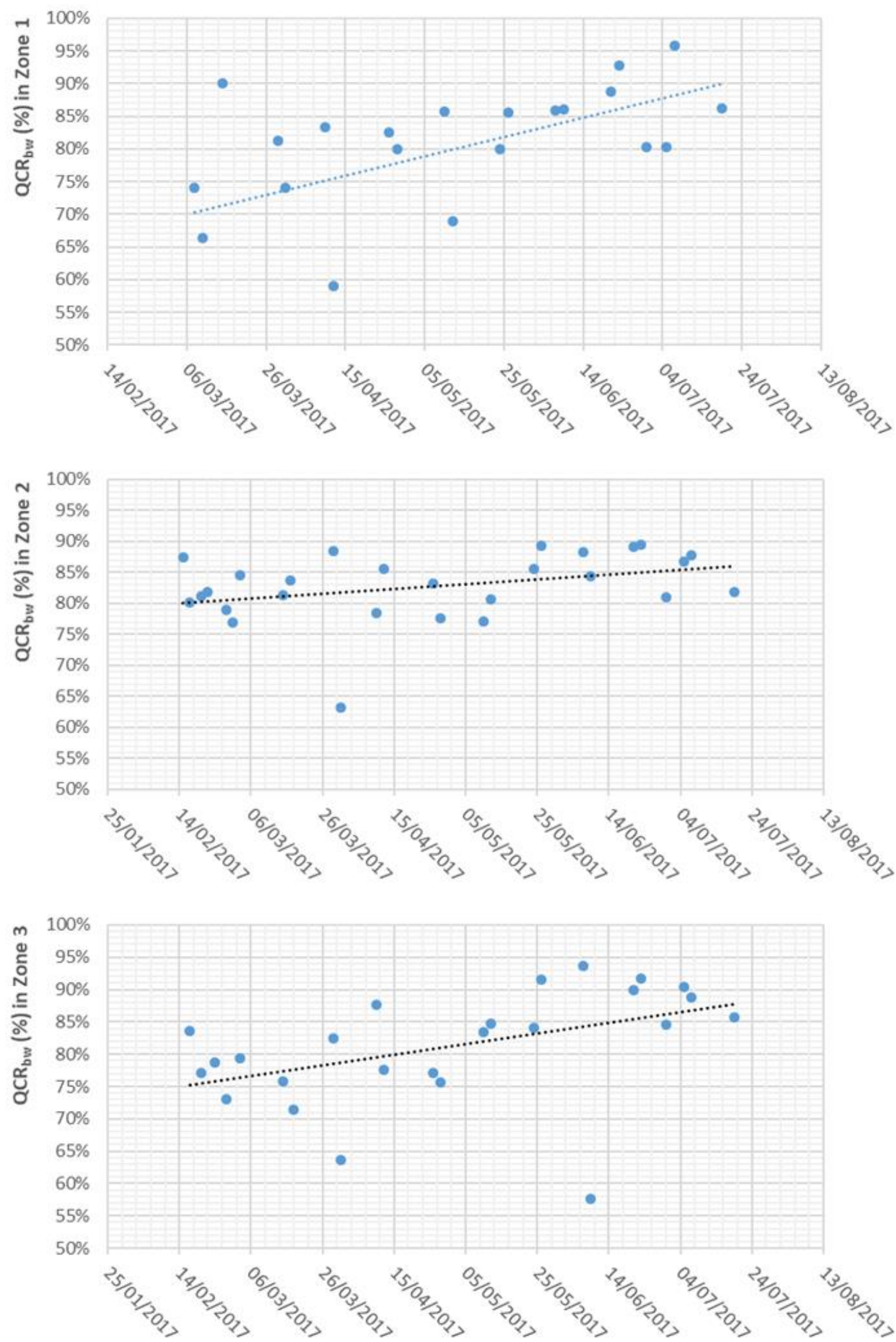

Fig. 2. Variation of $\mathrm{QCR}_{\mathrm{bw}}(\%)$ over time in Zone 1,2 and 3 
367 In the three zones, $\mathrm{QCR}_{\mathrm{bw}}$ values of around $90 \%$ are reached at the end of the experiment.

368 This increase may be mainly due to citizens' learning and familiarization with this new

369 separate waste collection, which implies an increase in their collaboration. Throughout

370 the experiment there was no reinforcement of information, so it follows that citizens

371 themselves voluntarily improved the quality of the waste in the container. Therefore, it is

372 assumed that this is the value that can be reached after its definitive implantation in the town and that, with a continuous awareness campaign, it could be maintained over time.

374

\subsection{The average composition of the waste in the mixed waste container}

Table 4 shows the average composition of the mixed waste container for zones 1, 2, 3 and

4. The characterization was carried out in the last month of the experiment, when the $\mathrm{QCR}_{\mathrm{bw}}$ of the selective collection was found to be higher.

According to the data in Table 4, despite the fact that selective collection of lightthese materials appear in the container in the four zones. It is also important to highlight that there are apparently no differences between the four zones.

Table 4: Composition of the waste in the mixed waste container

\begin{tabular}{|c|c|c|c|c|c|c|c|c|}
\hline \multirow{3}{*}{ Fraction } & \multicolumn{8}{|c|}{ MIXED WASTE (\%) } \\
\hline & \multicolumn{2}{|c|}{ Zone 1} & \multicolumn{2}{|c|}{ Zone 2} & \multicolumn{2}{|c|}{ Zone 3} & \multicolumn{2}{|c|}{ Zone 4} \\
\hline & mean & st. dev. & mean & st. dev. & mean & st. dev. & mean & $\begin{array}{l}\text { st. } \\
\text { dev }\end{array}$ \\
\hline Biowaste & 62.06 & 11.11 & 54.31 & 9.94 & 58.77 & 1.93 & 59.19 & 3.79 \\
\hline Inappropriate & 37.94 & 11.11 & 45.69 & 9.94 & 41.23 & 1.93 & 40.81 & 3.79 \\
\hline Metal packaging & 3.55 & 2.54 & 2.65 & 1.09 & 2.38 & 0.91 & 2.78 & 0.60 \\
\hline Other metals & 0.20 & 0.28 & 0.30 & 0.52 & 0.38 & 0.62 & 0.29 & 0.10 \\
\hline Clean paper/cardboard & 3.84 & 0.84 & 5.24 & 1.31 & 3.95 & 0.98 & 4.21 & 0.76 \\
\hline Dirty paper/cardboard & 5.26 & 3.76 & 3.58 & 2.09 & 3.06 & 1.16 & 3.91 & 1.11 \\
\hline Plastic packaging & 9.07 & 0.02 & 10.55 & 4.34 & 10.63 & 1.47 & 9.92 & 0.84 \\
\hline Other plastics & 0.60 & 0.68 & 5.43 & 6.47 & 2.22 & 2.04 & 2.68 & 2.39 \\
\hline Sanitary cellulose & 2.62 & 3.29 & 2.69 & 2.43 & 6.75 & 1.43 & 3.90 & 2.29 \\
\hline Beverages cartons & 0.46 & 0.19 & 1.94 & 1.61 & 1.65 & 0.28 & 1.31 & 0.77 \\
\hline Textile & 2.40 & 2.61 & 1.58 & 0.34 & 3.41 & 2.36 & 2.40 & 0.91 \\
\hline
\end{tabular}




\begin{tabular}{lllllllll}
\hline Others & 3.17 & 2.45 & 7.15 & 6.96 & 3.17 & 1.91 & 4.37 & 2.24 \\
Glass packaging & 6.80 & 2.00 & 4.57 & 0.26 & 3.64 & 0.09 & 4.87 & 1.57 \\
Fines & 0.00 & 0.00 & 0.00 & 0.00 & 0.00 & 0.00 & 0.16 & 0.03 \\
\hline
\end{tabular}

Thus, to determine statistically whether there are any significant differences between the 386 four zones regarding the percentage of biowaste in the mixed waste container, a comparison of means was conducted. For this purpose, the Kruskal Wallis test with a confidence level of $95 \%(\alpha=0.05)$ was used. We decided to employ this non-parametric test because the number of mixed waste composition data for each zone is small (three data).

From the results, it can be stated (with $95 \%$ confidence) that there are no significant differences in the percentages of biowaste in the mixed waste container between the four zones, since the p-value obtained is 0.7793 ( $p$-value $>0.05$ ). This is due to the fact that only a small part of the biowaste is diverted from the mixed waste container to separate biowaste collection, as indicated by the $\mathrm{SR}_{\mathrm{bw}}$ values shown in Table 5 . Therefore, the composition of the mixed waste container in Zones 1, 2 and 3 does not change significantly with respect to Zone 4 .

\subsection{Separate collection of the biowaste and its variation over time}

400

Table 5 shows the results of the collection in the three areas studied. The total amount of

401 waste monitored in the pilot study was $26,460 \mathrm{~kg}$, of which $21,725 \mathrm{~kg}$ corresponds to net biowaste (nbw). It should be noted that Zone 2 is the one where the largest amount of waste and biowaste was collected, despite being the zone with the least inhabitants. The lowest amount of waste was collected in Zone 1, but this is due to the fact that collection started 6 weeks later. 
Table 5: Results of the selective collection of biowaste

\begin{tabular}{|c|c|c|c|c|}
\hline Parameters & Zone 1 & Zone 2 & Zone 3 & Total \\
\hline Total gross biowaste $(\mathrm{kg})$ & 5,180 & 12,080 & 9,200 & 26,460 \\
\hline Total net biowaste (kg) & 4,184 & 10,051 & 7,491 & 21,725 \\
\hline Biowaste generation per year $(\mathbf{k g})$ & 291,922 & 139,898 & 216,354 & 648,174 \\
\hline Biowaste generation in the town $(\%)$ & 59.19 & 59.19 & 59.19 & 59.19 \\
\hline \multirow[t]{2}{*}{ Collection days } & 137 & 179 & 179 & 495 \\
\hline & & & & Mean \\
\hline $\operatorname{SR}_{b w}(\%)$ & 1.77 & 8.63 & 4.25 & 4.08 \\
\hline $\operatorname{NSR}_{b w}(\%)$ & 1.42 & 7.14 & 3.45 & 3.32 \\
\hline $\operatorname{QCR}_{\mathrm{bw}}(\%)$ & 79.75 & 82.74 & 81.18 & 81.22 \\
\hline$D_{C C R}$ gbw $(\mathrm{kg} / \mathrm{inh} \cdot \mathrm{day})$ & 0.010 & 0.047 & 0.023 & 0.026 \\
\hline $\operatorname{DCR}_{\text {nbw }}(\mathbf{k g} / \mathbf{i n h}-\mathbf{d})$ & 0.008 & 0.039 & 0.019 & 0.022 \\
\hline $\mathbf{C R}_{\text {bw }}$ (inh/cont) & 99 & 145 & 374 & 137 \\
\hline
\end{tabular}

409

410 Thus, in order to compare the amount of waste collected in each area, the gross and net

411 biowaste daily collection rates $\left(\mathrm{DCR}_{\mathrm{gbw}}\right.$ and $\left.\mathrm{DCR}_{\mathrm{nbw}}\right)$ were calculated. The gross biowaste

412 (gbw) includes the inappropriate fraction, and the net has only the biowaste. According 413 to the results in Table 5, the highest values correspond to Zone 2. Zone 1 presents the 414 worst results in $\mathrm{DCR}_{\mathrm{gbw}}$ and $\mathrm{DCR}_{\mathrm{nbw}}$, despite having the best $\mathrm{CR}_{\mathrm{bw}}$, which may be due to 415 the characteristics of the zone: a large number of shops, low population density and 416 elderly population. Zone 3 has lower values than Zone 2. These two zones have similar 417 characteristics in terms of population and endowment facilities. Therefore, the lower 418 values are exclusively due to their higher $\mathrm{CR}_{\mathrm{bw}}$, which means that citizen's collaboration 419 is lower, since the distance to the container is greater -a fact that was already confirmed 420 by Gallardo et al. (2010). The data are similar to those presented in Estonia (0.109 $421 \mathrm{~kg} /$ inhab·day) or Hungary $(0.05 \mathrm{~kg} / \mathrm{inhab} \cdot \mathrm{day})$, but far from other countries such as 422 Belgium (0.562 kg/inhab·day), Germany (0.499 kg/inhab·day), Finland (0.334 $423 \mathrm{~kg} / \mathrm{inh} a b \cdot$ day) or Italy (0.249 kg/inhab·day) (European Environment Agency, 2009). 
424 For the calculation of $\mathrm{SR}_{\mathrm{bw}}$ and $\mathrm{NSR}_{\mathrm{bw}}$, data about the collection of the mixed waste

425 fraction (fraction which includes the biowaste) for the entire city of Castelló and its

426 composition (see Table 4, Zone 4) are available. The $\mathrm{SR}_{\mathrm{bw}}$ and $\mathrm{NSR}_{\mathrm{bw}}$ values appear in

427 Table 5. These values are very low. The highest values are found in Zone 2, with an SR

428 of $8.63 \%$ and an $\mathrm{NSR}_{\mathrm{bw}}$ of $7.14 \%$, followed by Zone 3, with an $\mathrm{SR}_{\mathrm{bw}}$ of $4.25 \%$ and an

$429 \mathrm{NSR}_{\mathrm{bw}}$ of $3.45 \%$. However, in the waste directives, the EU promulgates that only $10 \%$ of

430 the waste will be deposited in landfills in 2030. For this reason, the waste management

431 system, especially in some countries, should improve considerably. This solution would

decrease the $\mathrm{CR}_{\mathrm{bw}}$. Another solution could be to separate the bio-waste at the source and

to collect it door-to-door. This system proved to be the best solution for the high public participation and the increase of the percentage of bio-waste in the collection ( $\mathrm{Li}$ et al., 2019). This decision coincides with studies conducted by Slavík et al. (2019), which fixed a series of factors that should be paramount in organizing the separate collection of biowaste, including the location of containers, and system parameters (e.g. volume of containers, frequency of collection). The results obtained from Slavík et al. (2019) confirmed how an intensive and adequate information campaign contributed to reduce the amount of improper waste in the bio-waste container. Furthermore, they observed that if the location of the containers was optimized and their number increased, the public participation was greater. Therefore, the proximity of the containers to the citizens, the door-to-door collection and the supply of compostable bags to the citizens was raised as

444 the best option from the citizen participation point of view and with the highest quality of bio-waste.

446 From an analysis of the previous data, it can also be concluded that the collection system

447 affects its performance, since each system defines the separation between containers differently and, therefore, its $\mathrm{CR}_{\mathrm{bw}}$. Therefore, in the pilot study that was carried out, it 

has been possible to show that, under the same characteristics of the population, the 450 collection system with a lower $\mathrm{CR}_{\mathrm{bw}}$ has a higher $\mathrm{SR}_{\mathrm{bw}}$.

451 To analyse the variation in $\mathrm{SR}_{\mathrm{bw}}$ throughout the experiment, the $\mathrm{SR}_{\mathrm{bw}}$ values of the three 452 zones have been represented on a graph (Fig. 3). The figure shows that in Zone 2 the $\mathrm{SR}_{\mathrm{bw}}$ 453 value increases significantly over time, in Zone 3 the increase was slighter, and in Zone 4541 it increased very little. This increase means that over the course of the experiment the number of participants also increased. It should be noted that the information campaign was only carried out at the beginning of the pilot study and there were no other reinforcement campaigns throughout the experiment but, even so, the data indicate that participation in the three areas increased.

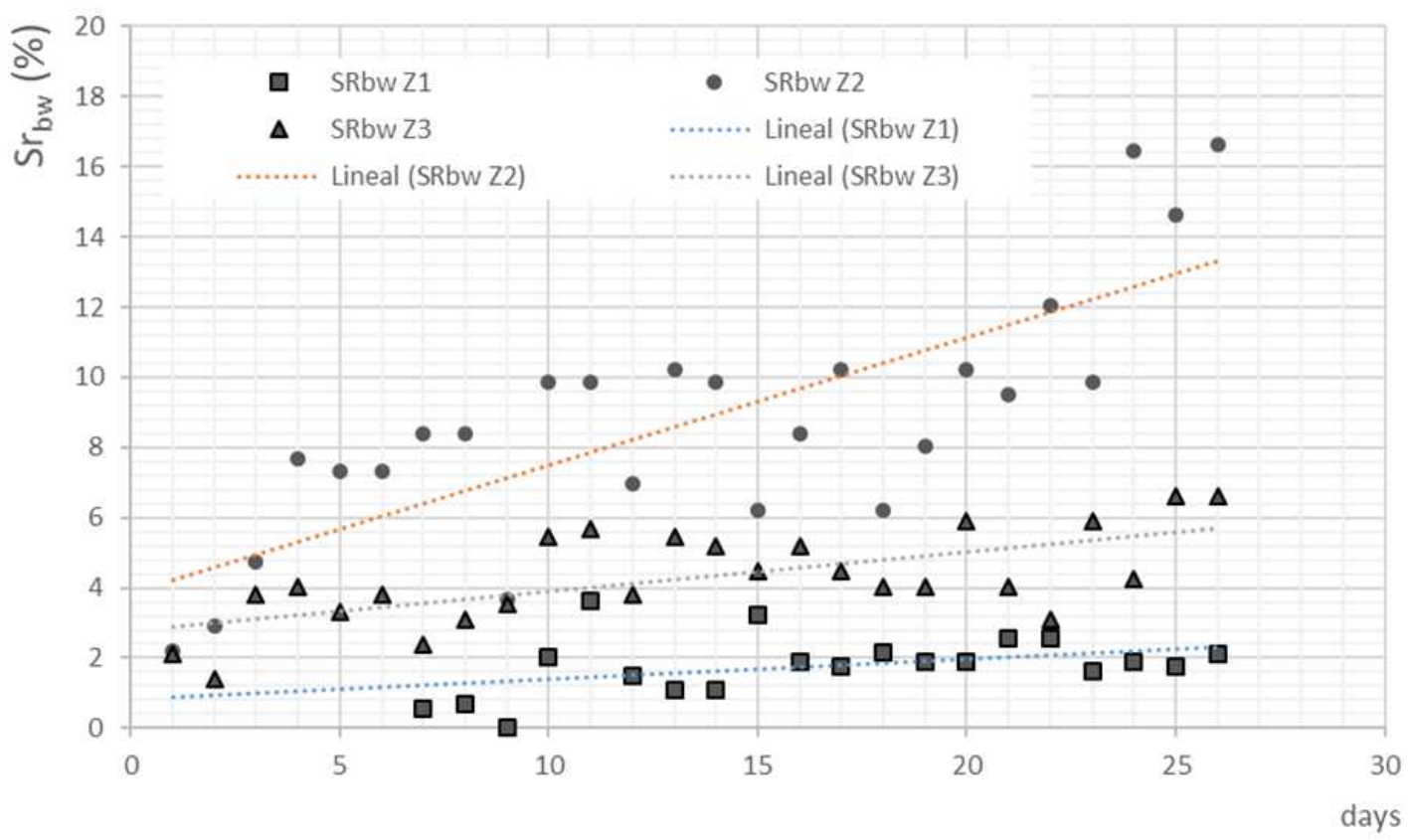

461 Finally, the increase in the $\mathrm{SR}_{\mathrm{bw}}$ and the $\mathrm{QCR}_{\mathrm{bw}}$ over time makes the last month the most efficient in the experiment. Therefore, these would be the data that could be taken as achievable when implemented throughout the city. Furthermore, this awareness is in 
accordance with a Eurobarometer survey on "Attitudes of European citizens towards the environment", in which it is concluded that $46 \%$ of Europeans (EU-28) considered the increasing amount of waste as one of the four biggest environmental problems in the EU. In fact, in the past six months, 66\% of Europeans (EU-28) separated most of their waste for recycling (European Commission, 2020).

\section{Conclusions}

471 This study presents a methodology to determine the degree of efficiency of the biowaste collection system. The results achieved are the first step towards improving a new biowaste collection system.

474 The study analyses the particular case of a pilot study of the selective collection of the 475 biowaste in Castelló de la Plana (Spain). The pilot scheme focuses on the current fraction 476 of mixed waste. From now on citizens should separate biowaste (brown container) and mixed waste (green container) at source.

Regarding $\mathrm{QCR}_{\mathrm{bw}}$ the study allowed the following issues to be determined:

- In the three areas, the $\mathrm{QCR}_{\mathrm{bw}}$ obtained is the same from the statistical point of view. Therefore, it has been shown that the citizens in the three areas separated their waste at source in a similar way.

- The percentage of inappropriate material is $20 \%$, consisting mainly of recyclable materials. To increase the $\mathrm{QCR}_{\mathrm{bw}}$, more information should be provided to citizens on how to manage food-containing packaging.

- It has been verified that in the three zones the $\mathrm{QCR}_{\mathrm{bw}}$ increased as the pilot study progressed, finally reaching $90 \%$. This increase may be due to citizen learning and familiarization with this new selective waste collection. Therefore, it is hoped 
that this is the value that can be reached after it is implemented definitively in the

489

490

491

492

493

494

495

496

497

498

499

500

501

502

503

504

505

506

507

508

509

510

511

512 city.

- Regarding the mixed waste container, the four zones present QCR $_{\text {bw }}$ values that are not statistically different. This fact shows that there has been no significant transfer of biowaste to the brown container.

On the other hand, regarding the amounts of waste collected separately in the brown container, this study allowed the following issues to be determined:

- Zone 1, with more commercial activity and older citizens, presents the worst results in $\mathrm{DCR}_{\mathrm{gbw}}$ and $\mathrm{DCR}_{\mathrm{nbw}}$, despite having the best $\mathrm{CR}_{\mathrm{bw}}$.

- On analysing the $\mathrm{DCR}_{\mathrm{gbw}}$ and $\mathrm{DCR}_{\mathrm{nbw}}$ from Zones 2 and 3 it has been shown that their value increases when $\mathrm{CR}_{\mathrm{bw}}$ decreases and, therefore, to have better results it will be necessary to decrease the $\mathrm{CR}_{\mathrm{bw}}$, that is, to reduce the distance from the citizen to the container.

- The $\mathrm{SR}_{\mathrm{bw}}$ increases in the three zones over time, although in different ways, which means that citizens' collaboration has increased.

- The collection system affects the $\mathrm{SR}_{\mathrm{bw}}$, since each system defines the separation between containers differently and, therefore, its $\mathrm{CR}_{\mathrm{bw}}$ will be different.

The increase in $\mathrm{SR}_{\mathrm{bw}}$ and $\mathrm{QCR}_{\mathrm{bw}}$ over time makes the last month of the experiment the most efficient. Thus, it can be said that there is a positive evolution of the experiment, which encourages implementation of the system throughout the city.

Finally, the proposed methodology and its results in the pilot study can be useful at the international level when implementing a separate biowaste collection system in a city with similar characteristics. 
513

514

515

516

517

518

519

520

521

522

523

524

525

526

527

528

529

530

531

532

533 Availability of data and materials: Not applicable; All the data with which this article

534 has been prepared is included in the article itself
Abbreviation list:

bw: biowaste

CR: containerization rate

DCR: daily collection rate

EU: European Union

gbw: gross biowaste

mx: mixed waste

nbw: net biowaste

NSR: net separation rate

QCR: quality in container rate

SR: separation rate

st. dev.: standard deviation

VC: variation coefficient
Ethics approval and consent to participate: Not aplicable

Consent for publication: Not aplicable 
536 Competing interests: The authors declare that they have no competing interests

537

538 Funding: The funds with which this research has been provided by the Universitat

539 Jaume I, the Castellón City Council and the FCC company

540

541 Authors' contributions:

542 AG has been the coordinator of the research, carried out the bio-waste characterizations,

543 managed the funds and negotiated with the companies. He has also collaborated in the

544 writing of the article analyzing data and drawing conclusions

545 FJCM participated in the characterizations of waste and coordinated the writing of the

546 article searching for similar works, summarizing references, discussing results and

547 drawing conclusions

548 MCA participated in the characterizations of waste and collaborated in the writing of

549 the article

550 CB managed the collection of waste in the city and its delivery on the designated days

551 NEA participated in the characterizations of waste

552 JEA participated in the characterizations of waste

553

554 Acknowledgments

555 We thank the City Council of Castelló de la Plana (Spain) and the company FCC MEDIO

556 AMBIENTE, S.A. (Spain) for their collaboration in carrying out the project.

557

558 References 
559 Alvarez MD, Sans R, Garrido N, Torres A (2008). Factors that affect the quality of the

560 bio-waste fraction of selectively collected solid waste in Catalonia. Waste management, $561 \quad 28(2): 359-366$

562 Bees AD, Williams ID (2017). Explaining the differences in household food waste 563 collection and treatment provisions between local authorities in England and Wales.

564 Waste Management, 70: 222-235

565 Boelens J, DeWilde B, DeBaere L (2013). Comparative study on biowaste definition: 566 Effects on biowaste collection, composting process and compost quality. Compost 567 Science and Utilization, 4(1): 60-72

568 Calabro PS, Komilis D (2019). A standardized inspection methodology to evaluate 569 municipal solid waste collection performance. Journal of Environmental Management, $570 \quad$ 246: 184-191

571 Dangi MB, Pretz CR, Urynowicz MA, Gerow KG, Reddy JM (2011). Municipal solid 572 waste generation in Kathmandu, Nepal. Journal of Environmental Management, 92: 240$573 \quad 249$

574 Directive 2008/98/EC of the European Parliament and of the Council of 19 November 5752008 on waste and repealing certain Directives https://eur-lex.europa.eu/legal576 content/EN/TXT/?uri=CELEX:32008L0098

577 Directive (EU) 2018/851 of the European Parliament and of the Council of 30 May 2018 578 amending Directive 2008/98/EC on waste (Text with EEA relevance) https://eur579 lex.europa.eu/legal-content/EN/TXT/PDF/?uri=CELEX:32018L0851\&from=EN

580 ECN, European Compost Network, 2020. Policy: Biowaste in Europe 581 http://compostnetwork.info/policy/ (accessed 13 March 2020). 
582 European Commission, 2004. Methodology for the analysis of solid waste (SWA- Tool) https://cordis.europa.eu/project/id/EVK4-CT-2000-00030/results/es (accessed 15

584 December 2017)

585 European Commission, 2020. Attitudes of European citizens towards the Environment. 586 Special eurobarometer 501. Directorate General of Environment. WABE 92.4 Kantar. 587 https://ec.europa.eu/commfrontoffice/publicopinion/index.cfm/survey/getSurveydetail/i nstruments/special/surveyky/2257

589 European Communities, 2000. Success stories on composting and separate collection.

590 Directorate-General for the Environment Unit E.3, BU-9 02/121. Compost brochure, 591 Brussels. https://ec.europa.eu/environment/waste/publications/pdf/compost_en.pdf

592 European $\quad 2019 . \quad$ Biodegradable Waste.

593 https://ec.europa.eu/environment/waste/compost/index.htm

594 European Environmental Agency, 2009. Diverting waste from landfill. Effectiveness of 595 waste-management policies in the European Union. European Union. Copenhagen. 596 https://www.eea.europa.eu/publications/diverting-waste-from-landfill-effectiveness-of-

597 waste-management-policies-in-the-european-union

598 Gallardo A, Bovea MD, Colomer FJ, Prades M, Carlos M (2010). Comparison of different 599 collection systems for sorted household waste in Spain. Waste Management, 30: 2430$600 \quad 2439$

601 Gallardo A, Bovea MD, Colomer FJ, Prades M (2012). Analysis of collection systems for 602 sorted household waste in Spain. Waste Management, 32: 1623-1633.

603 Gomes AP, Matos MA, Carvalho IC (2008). Separate collection of the biodegradable 604 fraction of MSW: An economic assessment. Waste Management, 28(10): 1711-1719 
Jedrczak A (2018). Properties of the organic fraction directed to biostabilization in MBT

606

607

608

609

610

611

612

613

614

615

616

617

618

619

620

621

622

623

624

625

626

627

628 installations during the heating season. Civil and Environmental Engineering Reports, 28: $65-78$

Kubule A, Klavenieks K, Vesere R, Blumberga D (2019). Towards Efficient Waste Management in Latvia: An Empirical Assessment of Waste Composition. Environmental and Climate Technologies, 23(2): 114-130

Kumar S, Dhar H, Nair VV, Bhattacharyya JK, Vaidya AN, Akolkar AB (2016). Characterization of municipal solid waste in high-altitude sub-tropical regions. Environmental Technology, 37(20): 2627-2637

Li X, Bi F, Han Z, Qin Y, Wang H, Wu W (2019). Garbage source classification performance, impact factor, and management strategy in rural areas of China: A case study in Hangzhou. Waste Management, 89: 313-321

Majid MR, Hwee OB (2007). Sustainable solid waste management for island resorts: potential for Perhentian Island, Terengganu. Presented at the 1st International Conference on Built Environment in Developing Countries (ICBEDC 2007), Pulau Pinang, Malaysia Morrissey AJ, Browne JB (2004). Waste management models and their application to sustainable waste management. Waste Management, 24(3): 297-308

Nhubu T, Muzenda E (2019). Determination of the Least Impactful Municipal Solid Waste Management Option in Harare, Zimbabwe. Processes, 7: 785

Pirani SI, Arafat HA (2014). Solid waste management in the hospitality industry: a review. Journal of Environmental Management, 146: 320-336

Puig-Ventosa I, Freire-Gonzalez J, Jofra-Sora M (2013). Determining factors for the presence of impurities in selectively collected biowaste. Waste Management and Research, 31(5): 510-517 
Puyuelo,B, Colon J, Martin P, Sanchez A (2013). Comparison of compostable bags and 630 aerated bins with conventional storage systems to collect the organic fraction of municipal 631 solid waste from homes. A Catalonia case study. Waste Management, 33(6): 1381-1389

632 Ricci M (2013). Biowaste Management in Italy and Quality Assurance. CIC- Consorzio 633 Italiano Compostatori / Italian Biogas and Composting Consortium.

634 Schuch A, Morscheck G, Lemke A, Nelles M (2017). Bio-Waste Recycling in Germany 635 - Further Challenges. Compost Science Utilization, 25: S53-S60

636 Slavík J, Rybová K, Dolejš M (2019). Biowaste separation at source and its limitations 637 based on spatial conditions. Detritus, 5: 36-45.

638 Tatano F, Caramiello C, Paolini T, Tripolone L (2017). Generation and collection of 639 restaurant waste: Characterization and evaluation at a case study in Italy. Waste 640 Management, 61: 423-442

641 Urban Waste (2020) Report: Selective collection of biowaste from hotels and restaurants. 642 http://www.urban-waste.eu/wp-content/uploads/2019/07/M05.pdf (accessed 20 March $6432020)$

644 Wang D, Tang Y, Long G, Higgitt D, He J, Robinson D (2020). Future improvements on 645 performance of an EU landfill directive driven municipal solid waste management for a 646 city in England. Waste Management, 102: 452-463

647 Závodská A, Benešová L, Smyth B, Morrissey AJ (2014). A comparison of biodegradable 648 municipal waste (BMW) management strategies in Ireland and the Czech Republic and 649 the lessons learned. Resources Conservation and Recycling, 92: 136-144 650 
Figures
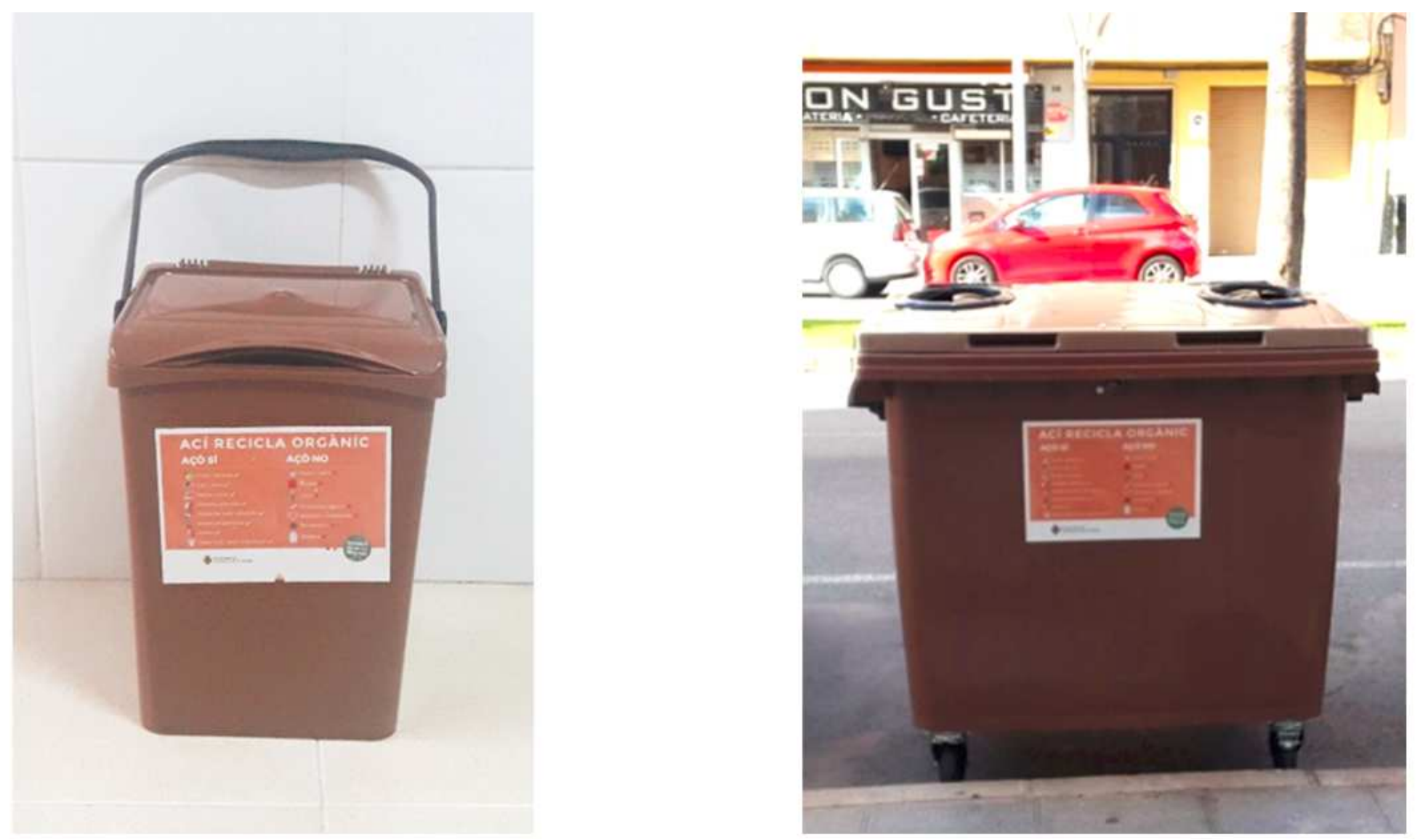

Figure 1

$10 \mathrm{~L}$ bin (left) and 1,100 L container (right) 

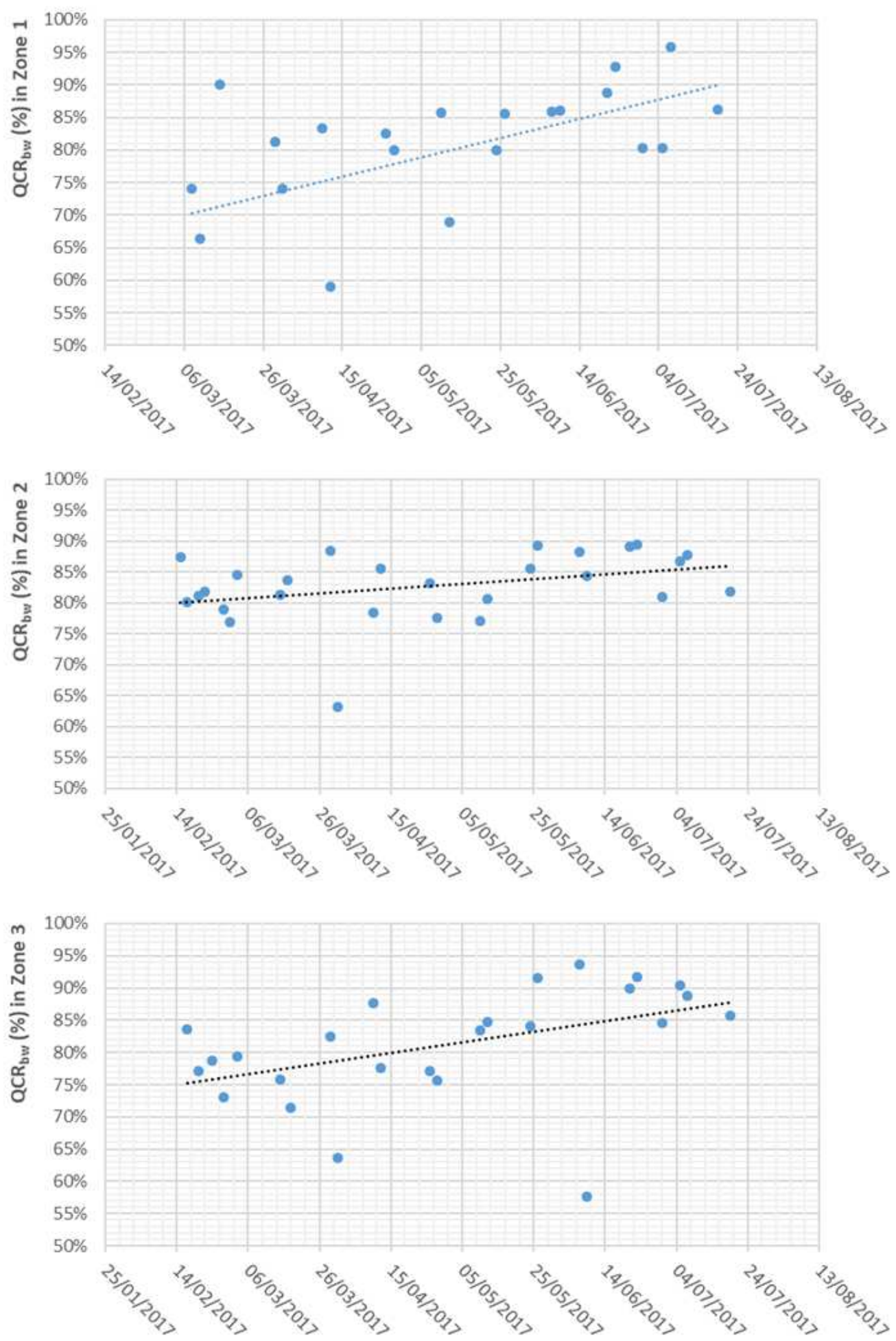

Figure 2

Variation of QCRbw (\%) over time in Zone 1, 2 and 3 


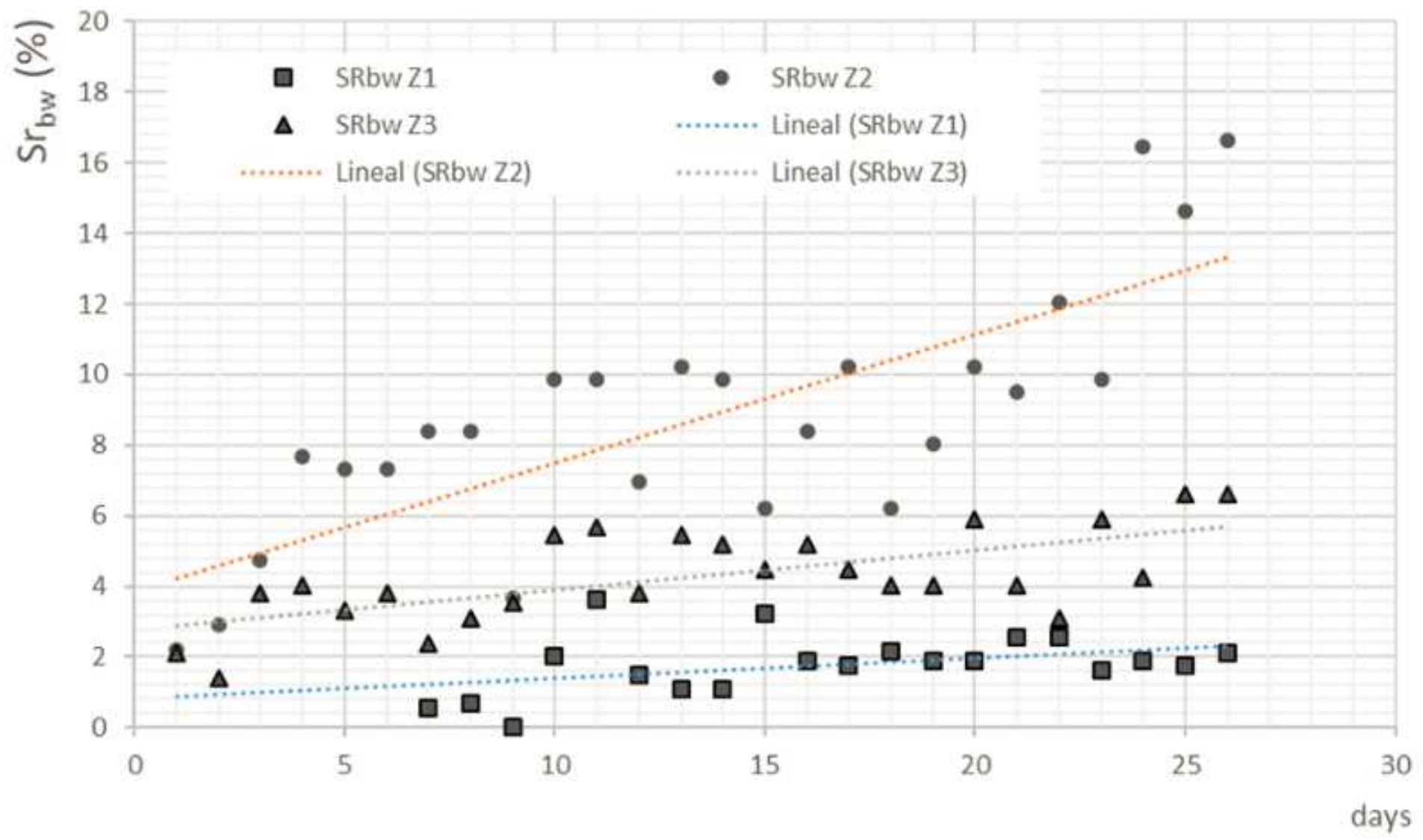

Figure 3

Variation in the SRbw over time 